\title{
Uncle Wuffle's Advice on Job Talks
}

\author{
A Wuffle, University of California, Irvine
}

G iving a job talk has multiple aims. Most important of these: to get a job. But, it also makes sense to think about a job talk as (a) practice that will improve your skills for future job interviews, making it more likely that you will eventually get a job, even if not this one, (b) a kind of initiation ritual into the profession, ${ }^{1}$ and (c) a way to broaden your academic network and make new friends. ${ }^{2}$ It is your chance to persuade your peers (and perhaps your future colleagues) that you are a promising/ accomplished scholar, a potentially good colleague, and a good teacher-not necessarily in that order. Priorities attached to these desiderata will vary from department to department (with major differences to be expected between research-oriented departments and those with a more liberal arts focus), but even within any given department, different members of the department will undoubtedly attach different weights to each of these three concerns. Such relevant information will be conveyed in a job talk.

I have divided the discussion in this essay into three sections: preparing the talk, giving the talk, and final points to remember. ${ }^{3}$ The advice below is predominantly intended for job talks at research universities, but almost all of it can be adapted to job talks at institutions where teaching ability is the principal evaluation criterion, and where talks may be before a primarily student audience. In giving a research talk, you want to demonstrate to the audience the specific areas of your particular expertise, but you also want to indicate that your overall interests range over a wider domain. But even research universities are interested in how/what you might teach. Similarly, departments oriented primarily to teaching will be interested in the quali-

A Wuffle is an associate to professor at the University of California, Irvine. Wuffle has published more than 13 articles, including such neglected classics as "The Pure Theory of Elevators," Mathematics Magazine 55 (1982): 30-37, and "Finagle's Law and The Finagle Point, a New Solution Concept for Two-Candidate Competition in Spatial Voting Games," American Journal of Political Science May (1989): 348-375, with Scott L. Feld, Guillermo Owen, and Bernard Grofman. ties of mind and breadth of knowledge your lecture displays. Moreover, all departments are interested in evaluating you as a potential long-term colleague.

\section{Preparing Your Job Talk}

1. In a job talk, the two most important things are to (a) clearly have something to say, and (b) be able to say whatever you have to say clearly. If you are presenting before a research-oriented audience, take for granted that you will be asked "Why should anybody care?" about your assertions/findings. If you don't have a plausible answer to that question, then the topic is not a good choice for a job talk. 4

2. Learn about your audience, preferably in advance (e.g., its size and balance of faculty, graduate students, and undergraduates). ${ }^{5}$ Modify your job talk in light of the knowledge and interests of your audience. A class lecture is not the same as a research-oriented talk before a faculty audience. For the former, research what the class has already learned and pitch your talk appropriately. For the latter, find out the specific interests and previous research of the department's faculty. Knowing those interests can help you shape your talk to link your field of research to that found among the department's faculty. ${ }^{6}$ A job talk is invariably before an audience of political scientists from many different subfields, who, in Gabriel Almond's classic phrasing, "sit at separate tables." Do not assume that your audience knows the same things you take for granted, or reads the same authors to whom you cite as shorthand. ${ }^{7}$

3. Learn the time constraints you'll be working under, and how much time should be spent on the presentation and how much left for the discussion. ${ }^{8} \mathrm{~A}$ job talk is different from the usual conference presentation in that it is much longer. In itself, that imbues the job talk with different advantages and challenges: it allows you time to give details that you'd otherwise have to omit; but it also allows you more time to bore the audience.

4. Every talk (whether in political theory, political economy, or somewhere in between) must have a coherent line of argument. Also, it helps to think of your presentation in terms of beginning, mid- dle, and end-as if it were a story. Always remember the debater's rule: At the very beginning of the talk tell them what you are going to say; tell them; then remind them what you've told them at the end of talk. Laying out the main concepts/hypotheses/findings at the beginning of the talk provides the audience a mental map so that they can better remember the substance of your presentation. Summarizing your presentation provides closure to a talk in much the same way that dessert and coffee do to a meal. ${ }^{9}$

5. A job talk differs from the usual conference presentation in that most of the faculty in the room have no inherent interest in your topic, nor any knowledge of the topic's literature (except possibly what they remember from graduate school). Therefore you must both "sell" the topic and explain the issues and key concepts far more than you would if you were speaking to an audience of specialists.

6. Another way a job talk differs from the usual colloquium or conference presentation is that you are selling yourself as well as your ideas. Before the formal presentation begins, prepare in advance a sentence or two (no more) to serve as an introduction and an elaboration on the kinds of topics and questions that make you want to be a political scientist. Make it clear that this talk, while perhaps illustrative of your talents and concerns, is not a full account of your abilities. This is especially important if you are presenting a chapter from your dissertation. Explain how this talk is only a piece of a bigger picture-one that you will be happy to talk about in the Q \& A session afterward.

7. Prepare notes to remind you of the points you need to cover, and the sequence in which you want to cover them. ${ }^{10}$ Job talks should not be read. ${ }^{11}$

8. Be selective. Avoid stringing together a long series of quotes, figures, or tables, unless they further a clear story line. Remember the advice of the legendary architect Mies van der Rohe: "Less is more."

9. PowerPoint is an increasingly important tool in a job talk. Use of PowerPoint alerts faculty that here is a scholar who (perhaps unlike themselves) is not afraid of computers. Use of PowerPoint also suggests a scholar who has given 
their ideas careful thought and can offer a logical flow to their arguments. PowerPoint also helps the audience focus on the main ideas in your presentation. A presentation with, say, seven main points, ${ }^{12}$ may be too difficult for your audience to keep track of without a visual aid. And, in the summary at the end of the talk, PowerPoint makes it easy to refer back to earlier slides. Similarly, if your key terms require lengthy definitions/operationalizations, a PowerPoint slide displaying this information can make things easier on your audience. Ditto for displaying long quotes on which you will commenting (as might be the case in a political theory or con law talk in political science). But PowerPoint is a tool, not a crutch, and should never be the entirely of the talk. In particular: (a) If you use PowerPoint, confine your slides to a handful of key points / definitions/results. Your slides should never contain so much text that, in effect, your talk consists of merely reading your slides to the audience. Don't present too many slides. ${ }^{13}$ You might also want to prepare some slides just as backups, to be used in response to potential questions. ${ }^{14}$ (b) Remember to use REALLY BIG PRINT, especially for tables and figures. There are few things more awkward than pointing to parameters in an equation or table only to discover that nobody can read them. ${ }^{15}$ (c) Make sure to check in advance the technological capabilities of the room in which you will present your talk. Is an LCD display of PowerPoint available? Can you just bring a smart key with your PowerPoint file, or do you have to bring your own laptop. Have a backup plan if PowerPoint crashes (e.g., transparencies that can be used with an overhead projector). I've been to too many talks where the communication between the speaker's laptop computer and the LCD met some technical glitch, leaving the speaker forced to put on an entirely verbal presentation. Indeed, if you really think it necessary for people in the audience to look at data shown in particular figures and tables, then make sure in advance how many copies you'll need, and bring that material as handouts. ${ }^{16}$

10. In private, practice and time your presentation so that you have a very good idea of its length, but take for granted that something will probably go wrong (maybe the presentation will start late; maybe you will be interrupted by questions) and think in advance about how to shorten it to keep within the time constraints while still conveying all the necessary information. However, it is not enough to rehearse your talk in private; you need to practice your job talk (a) in front of an audience, and (b) in a setting similar to that which you are expecting for the real thing. Use the transparencies or PowerPoint slides you expect to use in your actual talk in your practice talk. Follow the same time constraint in the practice talk that you will be restrained by on your real job talk. Don't reinforce a bad habit by reading your talk when you practice giving it. Even if the only person in the room is your mother, behave just as if you were giving a talk before an audience of strangers. Ideally, however, the audience for your practice talk should mirror that of the real thing, i.e., a mix of faculty and graduate students. $^{17}$

\section{Giving Your Job Talk}

11. Get a good night's sleep before your talk. A job interview schedule is usually pretty grinding, and you want to be at your best for your talk.

12. Go to the room in which your talk is being given early. Get set up so that the talk can begin immediately after you are introduced. ${ }^{18}$ If you have overheads or transparencies, check the presentation equipment to make sure you know how it works and that it does work. Try a sample slide in the overhead (or turn on the PowerPoint presentation) and go to the back of the room to check its legibility. ${ }^{19}$ All adjustments to the equipment should take place before the talk begins. Remember to pay attention to audience sightlines. Don't stand in a location which blocks the view of the screen for some portion of the audience. Don't turn your back on the audience.

13. Even if a copy of the paper that is the basis for your job talk has been distributed in advance, do not assume that anybody has read it.

14. While, in general, it is better to come off as charming, witty, and loveable than the opposites, don't get too cutesy. A job talk is not an audition for Comedy Central. If you don't appear to take the talk seriously, then neither will your audience. $^{20}$

15. Make your room presence dependent upon the room's layout. Some rooms provide space to circulate during your talk; others may dictate that you give your presentation entirely from behind a podium. There is no real rule here other than to do what is comfortable for you, but a middle ground is probably best: always stay at the podium and you may appear stiff; moving around too much may be annoying. ${ }^{2} 1$

16. Watch your audience. Don't be a prisoner to your notes. Based on what you sense from the audience, elaborate on some points and skip others. If you think the audience is bored, speed things up; ${ }^{22}$ if you think they are not following, go more slowly. Fast talkers can write points on the blackboard (or use PowerPoint) to slow down the flood of words and focus their audience on the critical points, helping dim-witted faculty focus on what the presenter is trying to say.

17. Don't be afraid to be interrupted during your talk for questions that clarify what you are about; but also don't be afraid to refuse to answer questions that get in the way of the flow of the talk. Politely explain that that point will be covered later in the talk. ${ }^{23}$

18. Listen carefully to questions and give a responsive answer. ${ }^{24}$ Job candidates are often judged more by how well they respond to questions than on the body of their presentation. ${ }^{25}$

19. Keep track of time. ${ }^{26}$ Never use up the time that has been reserved for discussion. Doing so is a breach of good manners and a guaranteed way to irritate some faculty. ${ }^{27}$

\section{Final Points to Remember}

20. The more senior you are, and the better your track record of achievements and honors, the more plausible it is for you to disregard any (or even all) of the above good advice. But, even for a very senior academic, bad job talks can be fatal. Academics are prey to the same kind of cognitive biases as were celebrated by Kahneman and Tversky, such as the "availability to memory" effect. Normally, a job talk will be the last and most permanent impression you leave on the faculty who will be deciding whether to hire you. ${ }^{28}$

21. However, there is no such thing as the perfect job talk. If you present a very tightly focused data analysis paper, you will be criticized for not having dealt with the bigger picture. If you present a more conceptual paper, you will be criticized for not having shown how the ideas can be empirically applied. If you focus too much on statistical details you will be criticized for being a narrow number cruncher, and you are also apt to put most of the audience to sleep. If you skip over statistical and research design complexities, there will be worries that you are only capable of "cookbook" statistics. All you can do is your best.

22. Moreover, the job talk, while very important, is still only a part of the interview process. Meeting people is also an important part of any interview. In talking to faculty closest to your research interests you can "talk shop" and discuss details of your work; these faculty are usually the people their colleagues rely upon to give an evaluation of your 
technical competence in the subfield. To others, try to show the extent to which you are a very broadly-read scholar and not a narrow specialist. ${ }^{29}$ But faculty are not the only people you will be meeting. Always be nice to staff and students. It's the right thing to do in all cases, and it's the expedient thing to do on job interviews. $^{30}$

23. While it is a very bad idea to nag your hosts for a quick decision as to whether you have been hired, it is impor- tant to ascertain when a decision might be expected. Moreover, if your own situation changes (e.g., you have another job offer, or you have a paper that has just been accepted for publication, or a book contract awarded), it is very appropriate for you to inform your hosts.

24. A job interview is not quite the same thing as a social occasion in that a thank you note to all your hosts is not needed; still, for the people who have gone to a lot of work to organize your visit (including the secretarial staff), and for people who have gone especially out of their way to be nice to you, a note of appreciation can't hurt. ${ }^{31}$

25. Last but not least, do not allow a negative decision to destroy your selfconfidence. In job interviews, as in publication submissions, a necessary attribute for any successful academic is a thick skin, and the resilience of a rubber ball. Do the arithmetic! Most applicants get turned down. ${ }^{32}$

\section{Notes}

1. A job interview is a learning experience. Regardless of whether you get the job, giving talks at universities helps socialize you to the norms of the profession, and gives you a far better appreciation for the fact that not all departments are like the one in which you got your $\mathrm{Ph} . \mathrm{D}$. or at which you are presently teaching.

2. For example, while Wuffle's present office-mate, Bernie Grofman, was still a graduate student, he interviewed unsuccessfully for a job at Rochester. While there he met a number of faculty whose work he admired, including William Riker, chair of the department, and several graduate students who are now famous names in political science. Even though Riker didn't offer him a job, over the years Grofman became better acquainted and solidified friendships with Riker and several of the others. (On the other side of the coin, Arend Lijphart interviewed many years ago at UCI, UCLA, and UCSD, and, offered jobs at all three, chose to go to San Diego. But while he was at UCI he and Grofman discovered lots of interests in common-eventually leading to their three coedited books, a jointly-taught course, and current book project.)

3. The inspiration to write this essay came from two UCI graduate students in political science: Becki Scola and Michele Budz. The ideas in it come from 30 years of listening to job talks: the good, the bad, and the ugly. Useful suggestions and corrections were made by Louis DeSipio, Amihai Glazer, and Elizabeth Loftus, as well as Stephen Yoder at $P S$; with the most extensive additions from Tallulah, a senior political scientist at UCI who is a forever young old friend of A Wuffle. However, none other than the author bear responsibility for the essay's final contents. This essay is a belated addition to the series of "Uncle Wuffle" essays providing an insider perspective on academia published in $P S$ in the 1980s and early 1990s, including Wuffle (1984, 1986a, 1986b, 1989, and 1993).

4. If you could not give a talk that would plausibly answer this question, then seriously consider a career outside of academia.

5. Be prepared to revise your expectations and the behavior based on them, however, when you are actually in the room. For example, as Tallulah recently reminded him, when, many years ago, Wuffle asked her to give a talk in political science at the University of California, Irvine, he told her the audience would consist mostly of political science undergraduates. She arrived to a room whose small crowd included graying and balding economics, cognitive science, and political science faculty of great distinction, with nary an undergraduate in sight.

6. Try to learn (and memorize) in advance the names of the faculty you expect to meet, and get at least some feel for the areas of research where there are concentrations of faculty. Also, try to remember the names of the people to whom you are introduced when you arrive on campus. Few things are more flattering to a junior faculty member than to learn than someone knows who they are; and few things more annoying to a self-proclaimed "well-known" senior faculty member than to realize that the person to whom they are being introduced has never heard of them or their work (Wuffle 1989, 839). Still, as my senior colleague Tallulah reminds me, knowing everybody's name and what they do is a virtually impossible task if a job talk is at a large department (indeed, it is a task that some faculty members at that department probably haven't mastered), so focusing on it will only make a job candidate tense and uptight. And even more importantly, good faculty don't really care if you know about their work-though egos being what they are, it doesn't hurt-but they do care about what you know about your work, and being relaxed and comfortable in your own area of expertise is far better than faking knowledge of a field not your own.

7. For example, "if we compare our results to Arrow's famous theorem" will be meaningless gibberish to some people in most audiences and to most people in some audiences, but the same is true for the phrase: "from a Habermasian ideal speech perspective."

8. Also, learn if there are any special "local norms." For example, at the University of California, Irvine anyone giving a job talk is asked by the chair of the department at the end of the presentation: "What would you like to teach?" If you are giving a talk at UCI it helps to have thought about the answer to this question in advance. Indeed, regardless of where you are giving a talk, assume that faculty there will want to know about both your teaching interests and your previous teaching experience.

9. Repetition of the key points need not be the very last part of the talk; you may wish to end with a discussion of where to go from here. Alternatively, if you really have a good punch line, e.g., if the theme of your talk is an empirical puzzle (Grofman 2002), then you might want to start the talk with the puzzle, and end the talk with the solution.

10. Notes can be on index cards or on a yellow pad or in a document on your laptop. But you need to be comfortable enough with the material that you can look down quickly at your notes and then just talk. MAKE SURE YOUR NOTES ARE LEGIBLE.

11. Reading directly from a paper that can be/has been made available to the audience seems to require a belief in one or more of the following propositions: (a) diligence requires that the presenter devise the perfectly precise wording of the argument and supporting materials, and not deviate from it lest $\mathrm{s} / \mathrm{he}$ loses the thread of her/his own argument and thus appear to be an idiot; (b) the folks in the audience are too lazy/stupid to read your paper, so you have to read it to them, word for word; (c) spontaneity is a bad thing. I should also note that there are few things more boring that to have a paper read to you. This procedure also tends to prevent any interchange between the paper-giver and the audience until the presentation is complete. And, perhaps most importantly (outside of philosophy, and some other areas of the humanities, where having papers read is common), seeing a presenter read a paper suggests to the audience that the paper-giver doesn't really know the material.

12. You should never have more than seven main points. This paper is, of course, an exception to the rule (but even we have the paper organized into only three sections).

13. How many slides are too many varies with the nature of the topic. If you have lots of data to review, then more slides may be needed. But don't try to present everything during your talk; rather, illustrate the main results with the slides. (Recall the earlier quote from Mies van der Rohe.) Esoteric complications (e.g., the table that shows that you get essentially the same results when you use Schmaltz's correction for panel-corrected errors in page proofs and thaumaturgy in the omitted variables as the ones you reported using non-standard ESL) should be omitted from the actual presentation and left to the discussion - preferably the one held later over a beer with the one or two people in the audience who will actually care/understand such things.

14. Such "extra" slides can be very effective since having a slide that directly responds to an (unplanted) question from the audience suggests that you really have put a great deal of thought into the issues involved.

15. You may well have to redo and simplify your data tables to make them easier to read as PowerPoint slides. If you can, take the time to do this; it's worth it. However, in any case, remember that most people in the audience will not be anywhere near as interested in the details of your tables as you are. For more on the effective use of PowerPoint in an academic presentation, see Hassner 2005. Hassner identifies both the advantages and the drawbacks of PowerPoint and has some very helpful advice, e.g., don't use features of the presentation software such as those that allow you to rotate headings or do wipeout effects unless you have very good reasons to do so; they will normally merely be distracting. 
16. As my colleague Tallulah points out, knowing that you have a backup if there is a computer glitch will diminish anxiety levels.

17. The more diverse this audience is for your practice talk, the more likely it is that you will receive feedback that will allow you to improve the presentation.

18. If it hasn't been done for you, clean the whiteboard. Also, get any extraneous items out of sight.

19. That way you won't need to waste time by asking the audience, "Can you see?" You should already know the answer to that question.

20. Also, especially for junior people, wear whatever is standard and looks professional. The focus of the talk should be on the ideas of your presentation; the audience probably ought not to remember what you wore.

21. My present office mate, Bernie Grofman, at a very early stage in his career (before he had formally received his Ph.D.), was a discussant on a paper by James Buchanan (already a very famous scholar, but not yet a Nobel Laureate). Grofman was (and is) a very peripatetic soul, and he went striding about the hall as he gave his discussant comments. A few minutes into his remarks, Buchanan interrupted him with the sharp injunction: "Don't just say something, stand there!"

22. There is a word of caution here: my senior distinguished colleague Tallulah, thinks that one can easily err here, misinterpreting quiet for boredom, so don't cut too much on the basis of a false read of the audience mood. She suggests a general rule: "If they look at their watches it's still OK; when they start shaking the watches to see if they're still running, that's not good."

23. It helps to check in advance the conventions of the department at which you are giving the talk. In some places it is the norm to hold questions to the end; in others it is often more of a free-for-all.

24. In an interview situation in a large department, when a job candidate has been introduced to many people in a short space of time, as noted earlier, it's not reasonable to expect that candidate to remember everybody's name. Still, it really makes people feel good if a job candidate can respond to their questions by calling them by name. But if in doubt, eschew the potential for error.
25. Also, don't allow yourself to be flustered by hostile tone to a question. Sometimes this is merely a ploy to see whether you can respond to criticism in a professional manner. Sometimes, of course, it does simply reflect hostility, but the nature of your response should be the same in either case. Nothing should fluster you. For example, my senior colleague, Tallulah, pointed out the story (possibly apocryphal) of a job candidate who had marshmallows thrown at her during a job talk, as an indication by a rather eccentric faculty member-who had just completed grocery shopping-that her talk was "soft." (Tallulah thinks you can write this off as bad manners on the part of the faculty, not as a serious comment on the talk.)

26. In particular, it's really embarrassing if you run out of time before you can get to the conclusion.

27. After all, you've denied them the opportunity to ask the question they had to ask, and thus to demonstrate their erudition and smarts before their colleagues.

28. Indeed, the concrete impression left by one bad job talk might overcome the weight of even dozens of first-rate articles in first-rate journals listed on a C.V., especially since most faculty will not have had time to read any of these articles, or at most they might look at one or two, and won't remember the ones they did read.

29. While, as suggested earlier, honesty is a very good policy, and you should never try to be something you are not, when a faculty member tells you of his/her interests, avoid responses of the form: "well, you may find that of interest, but that's not really my cup of tea." If someone you meet wants to give you a paper of theirs or a free copy of their book, look pleased to get it-even if you really don't have enough room in your bags to pack it. On the other hand, while it is not unreasonable to carry a few extra copies of papers of your own and to give them to faculty members who appear interested, don't overdo it-most faculty, already years behind on their reading, probably won't be interested.

(Here a story in the life of A Wuffle may be pertinent: According to the recollections of his colleague, Tallulah, at her wedding to her spouse, now more than two decades ago, Wuffle brought two copies of "The Collected Wit and Wisdom of A Wuffle" as his wedding gift, telling the happy bride and groom that they now would "not have to fight about who got the one copy if the marriage ended in divorce." This gift is still remembered.)

30. For example, at UCI, some years back, at least one job candidate was ruled out in part because his/her autocratic manner in communicating with the departmental secretary told us this was not somebody we wanted as a colleague. And, at UCI (as at other departments) graduate students are likely to be asked to provide feedback on the talk, especially as it relates to the impressions they formed about the likely teaching skills of the job candidate. Also, while social manners are in no way a job requirement, lack of social manners can be somewhat prejudicial if they suggest flaws related to collegiality. For example, if you are taken out several times to lunch and dinner, it's probably a bad idea to always order the most expensive item on the menu. In particular, as my senior colleague Tallulah reminds me, it is a definite "no, no" to get sloshed at a job-talk dinner. (Tallulah once saw an otherwise viable candidate do this-and it was no fun to watch.)

31. Similarly, if there are people who have given you copies of their papers/citations to their work, a follow-up acknowledgement suggesting that you may have actually read what they gave you/referred you to is never a bad idea.

32. Many times there will be idiosyncratic reasons (e.g., overriding curricular concerns) that can help explain why even a superbly qualified candidate may not be offered a particular job. For more on what departments are looking for in the academic hiring process, and on what you can do to make it more likely that you will get a job interview in the first place see Carter and Scott 1998 and Fuerstman and Lavertu 2005. For more advice on a how to have a successful campus visit in much the same spirit as the present essay, see Gould and Keeter 2003. These authors also consider what departments should do to help make job interviews run more smoothly, as do Furlong and Furlong 1994, who look at the job search process from the standpoint of a couple who are each looking for an academic job.

\section{References}

Carter, Ralph G., and James M. Scott. 1998. "Navigating the Academic Job Market Minefield." PS: Political Science and Politics 31 (3): 615-22.

Fuerstman, Daniel, and Stephan Lavertu. 2005. "The Academic Hiring Process: A Survey of Department Chairs.” PS: Political Science and Politics 38 (October): 731-36.

Furlong, Deborah K., and Scott R. Furlong. 1994. "Netting the Big One: Things Candidates (and Departments) Ought to Know." PS: Political Science and Politics 27 (1): 91-7.

Gould, Jon B., and Scott Keeter. 2003. "No Second Chance at Making a Good First Impres- sion: Peril and Possibility in the Campus Visit." PS: Political Science and Politics 36 (October): 791-794.

Grofman, Bernard, ed. 2002. Political Science as Puzzle Solving. Ann Arbor: University of Michigan Press.

Hassner, Ron E. 2005. "Sliding into Home Plate: How to Use Slideware to Improve Your Presentation (While Dodging the Bullets)." PS: Political Science and Politics 38 (July): 393-97.

Wuffle, A. 1984. "Advice to the Expert Witness in Court." PS: Political Science and Politics 17: $60-61$.
Wuffle, A. 1986a. "Reflections on Academia." PS: Political Science and Politics 19: 57-61.

Wuffle, A. 1986b. "Everything you Always Wanted to Know about Parliamentary Procedure in an Academic Senate and Were Afraid to Ask," PS: Political Science and Politics 19: 661-668.

Wuffle, A. 1989. "Advice to the Advanced Graduate Student." PS: Political Science and Politics 22(4): 838-839.

Wuffle, A. 1993. "Advice to the Assistant Professor." PS: Political Science and Politics 26: 89-90. 